\title{
Folate Cofactors Regulate Serine Metabolism in Fetal Ovine Hepatocytes
}

\author{
MICHAEL R. NARKEWICZ, GAYLE JONES, HENRY THOMPSON, FRED KOLHOUSE, AND \\ PAUL V. FENNESSEY \\ Department of Pediatrics, Sections of Pediatric Gastroenterology, Hepatology, and Nutrition [M.R.N., \\ G.J., H.T.], and Genetics [P.V.F.], and the Department of Medicine, Division of Hematology [F.K.], \\ University of Colorado School of Medicine and The Children's Hospital, Denver, Colorado 80218, U.S.A.
}

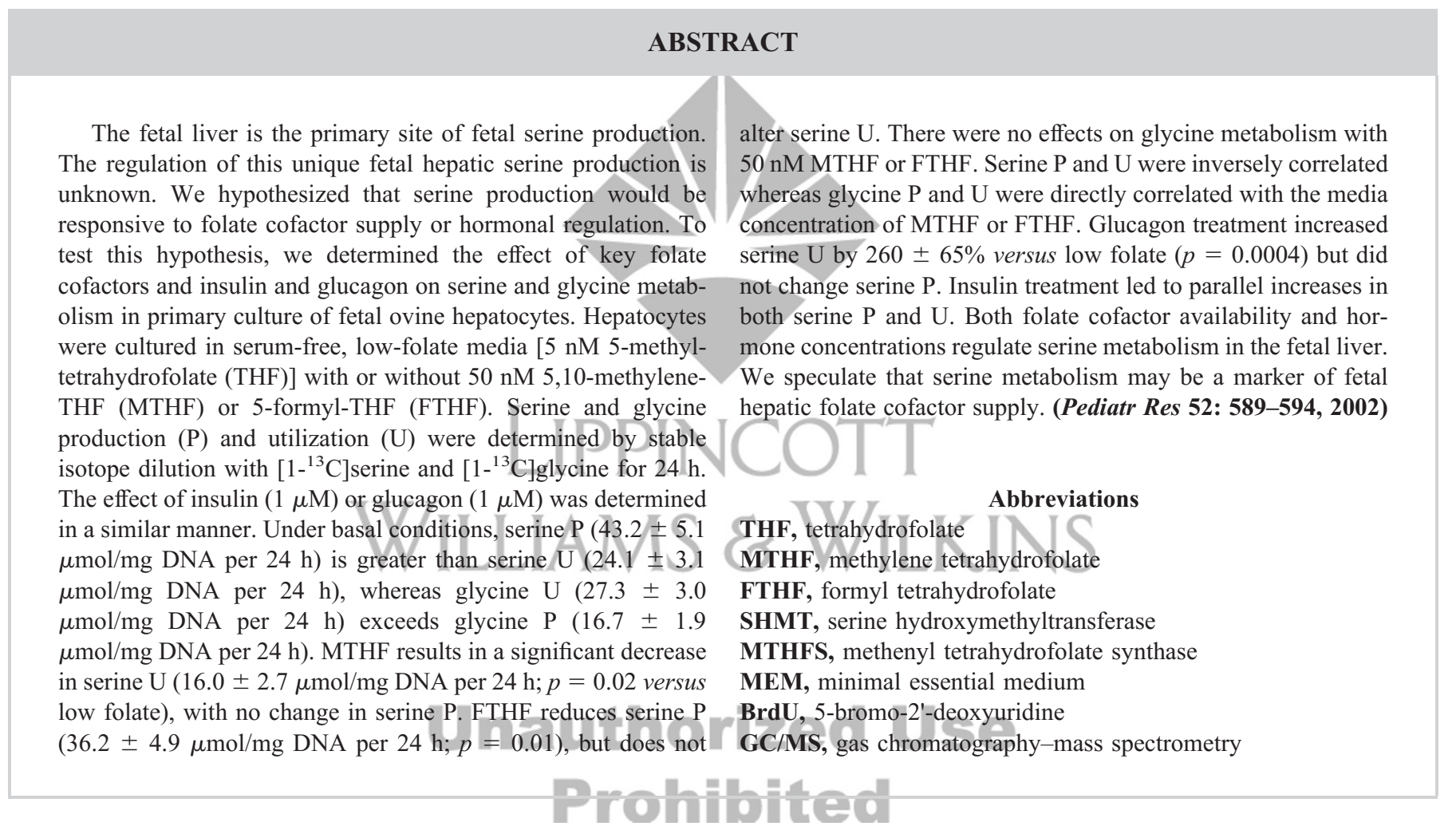

Serine occupies a unique metabolic position in the fetus. Studies in the fetal sheep demonstrated that serine is one of only three amino acids to have a net production across the fetal liver $(1,2)$. However, serine is poorly transported across the placenta to the fetus $(3,4)$. Thus, the fetus must rely on endogenous production of serine to meet the majority of its serine requirements. Serine is an important amino acid for DNA and RNA synthesis and phospholipid synthesis $(5,6)$. In human fetuses, serine metabolism is similar to that of fetal sheep $(7,8)$. Indeed, human fetuses that are small-forgestational age have selectively low levels of serine and gly-

Received March 5, 2002; accepted May 9, 2002.

Correspondence: Michael R. Narkewicz, M.D., Children's Hospital, B290, 1056 East 19th Avenue, Denver, CO 80218, U.S.A.; e-mail: narkewicz.michael@tchden.org

Supported in part by NIH grants HD 31648 (M.R.N.), HD 04024, HD 20761, DK 48520, and NIH training grant 5 T32 DK07038 (H.R.T.).

DOI: 10.1023/01.PDR.0000028054.99862.35 cine, suggesting an important role for serine in fetal growth $(8-10)$.

Little is known about the regulation of fetal hepatic serine metabolism. Others and we have demonstrated that the majority of serine produced by the fetal liver is derived from glycine $(2,11,12)$. However, the regulation of fetal hepatic serine metabolism is unclear. It is now clear that fetal hepatic serine synthesis is not dependent on the ontogeny of the key enzymes of serine metabolism (Fig. 1) (13) or substrate availability (11, 14).

Serine and folate metabolism are directly linked. Studies in neuroblastoma cells that over-express MTHFS found a significant increase in serine production (15). This increase in production appears to be directly related to an increase in the availability of MTHF and a decrease in FTHF. Only limited data are available on fetal folate metabolism. Folate is both actively and passively transported across the placenta. At 


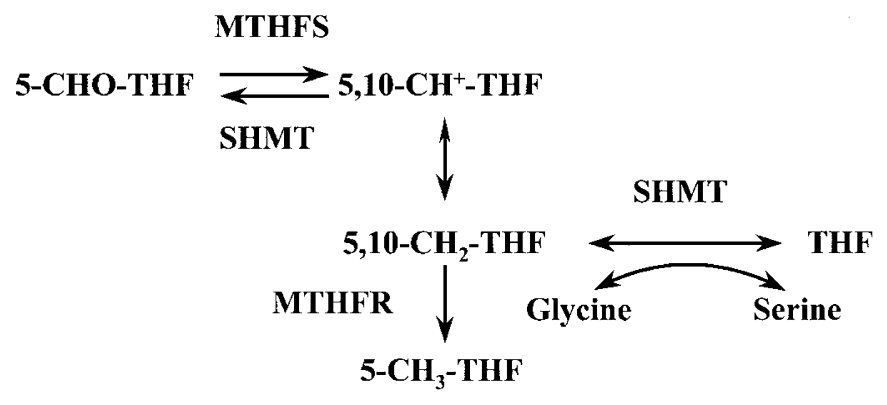

Figure 1. Metabolic pathway of serine and folate metabolism. MTHFR, methylene-THF reductase; 5,10- $\mathrm{CH}^{+}-\mathrm{THF}, 5,10$-methenyl-THF; 5, 10- $\mathrm{CH}_{2}-$ THF, MTHF; 5- $\mathrm{CH}_{3}-\mathrm{THF}$, 5-methyl-THF; 5-CHO-THF, FTHF.

midgestation, only a small amount $(0.5 \%)$ of maternal folate is found in the fetus, primarily in the fetal liver (16). During the third trimester, there is a more significant transfer of folate to the fetus, primarily to the liver. We have previously demonstrated that the ontogeny of the key enzymes of folate metabolism is consistent with a role in the regulation of fetal hepatic serine metabolism (17). In addition, we have shown that fetal ovine hepatocytes are an excellent model in which to study fetal hepatic serine metabolism $(11,12,18,19)$.

Based on these observations, we hypothesized that the relative supply of MTHF and FTHF to fetal ovine hepatocytes would alter serine metabolism. Specifically, we hypothesized that MTHF would increase net serine biosynthesis in fetal ovine hepatocytes. To test this hypothesis, in the first part of this study, we determined the effects of MTHF and FTHF on serine and glycine metabolism in fetal ovine hepatocytes.

Shortly after birth, there is a change from net hepatic serine production to net hepatic serine/utilization (20). Coincident with this change, there is an increase in the activities of the enzymes for the use of serine for gluconeogenesis $(21,22)$. Inasmuch as induction of gluconeogenesis is linked to hormonal changes that occur at birth (23), it is possible that the change in serine metabolism at birth is in part related to changes in glucagon and insulin that occur after birth. Thus, the second goal of this study was to determine the effect of insulin and glucagon on serine and glycine metabolism in fetal ovine hepatocytes.

\section{MATERIALS AND METHODS}

Materials. Media used for these studies was standard $\operatorname{MEM} \alpha$ compounded without any added glucose, folic acid, pyridoxine, or arginine, supplemented with $0.4 \mathrm{mM}$ ornithine, prepared by Cell and Molecular Technologies, Inc (Lavallette, NJ, U.S.A.). MTHF, FTHF (6S or $6 \mathrm{R}+\mathrm{S}$ ), and 5-methylTHF were from Schircks Laboratories (Jona, Switzerland). Stock solutions for culture were prepared as $\times 100$ stock solutions in $1 \%$ ascorbic acid, sterilized by filtration, and stored at $-20^{\circ} \mathrm{C}$ until added to cultures. $1-\left[{ }^{13} \mathrm{C}_{1}\right]$ serine was from Cambridge Isotope Laboratories (Woburn, MA, U.S.A.), and $1-\left[{ }^{13} \mathrm{C}_{1}\right]$ glycine was from Isotec, Inc. (Miamisburg, $\mathrm{OH}$, U.S.A.). Stock solutions were prepared in sterile deionized water, filter sterilized, and added to media just before use. Pyridoxine and collagenase $\mathrm{H}$ were from Boehringer Mann- heim Corp. (Indianapolis, IN, U.S.A.). Glucagon was from Eli Lilly and Co. (Indianapolis, IN, U.S.A.), and purified pork insulin was from Novo Nordisk A/S (Bagsvaed, Denmark). All other chemicals were from Sigma Chemical Co. (St. Louis, MO, U.S.A.) and were of the highest grade available.

Hepatocyte preparation. Fetal ovine hepatocytes were isolated by perfusion and collagenase digestion of the left lobe of the liver using techniques previously described except that collagenase $H$ was used $(11,18)$. In brief, the portal vein of the left lobe was catheterized with a $6 \mathrm{~F}$ catheter and perfused with calcium-free HEPES buffer (10 mM HEPES, $138 \mathrm{mM} \mathrm{NaCl}, 3$ $\mathrm{mM} \mathrm{KCl}, 0.7 \mathrm{mM} \mathrm{Na}_{2} \mathrm{HPO}_{4}, \mathrm{pH}$ 7.6). After $10 \mathrm{~min}, 0.025 \%$ collagenase $\mathrm{H}$ and $2.2 \mathrm{mM} \mathrm{CaCl}_{2}$ were added to the perfusate. After collagenase digestion, hepatocytes were filtered through mesh, isolated by centrifugation, and washed three times with media. Hepatocyte viability as determined by trypan blue exclusion was $>95 \%$ for all cultures. After isolation, hepatocytes were plated in standard MEM (GIBCO, Grand Island, NY, U.S.A.) supplemented with $10 \mathrm{nM}$ dexamethasone, 10 $\mathrm{IU} / \mathrm{mL}$ penicillin, $100 \mu \mathrm{g} / \mathrm{mL}$ streptomycin, $50 \mu \mathrm{g} / \mathrm{mL}$ kanamycin, and $10 \% \mathrm{FCS}$. After $4 \mathrm{~h}$ for adherence, the media was changed to MEM $\alpha$ supplemented with $5 \mathrm{nM} 5$-methyl-THF, $0.4 \mathrm{mM}$ ornithine, $1.1 \mathrm{mM}$ glucose, $2 \mathrm{mM}$ lactate, $0.2 \%$ albumin, $10 \mathrm{nM}$ dexamethasone, $10 \mathrm{IU} / \mathrm{mL}$ penicillin, 100 $\mu \mathrm{g} / \mathrm{mL}$ streptomycin, and $50 \mu \mathrm{g} / \mathrm{mL}$ kanamycin (low-folate media) without FCS and with folate cofactors from $50 \mathrm{nM}$ (physiologic concentration) to $2000 \mathrm{nM}$ (supraphysiologic). Before any manipulations, hepatocytes were cultured for $24 \mathrm{~h}$ in low-folate media to further folate deplete the cells. Thereafter, media was changed every $24 \mathrm{~h}$ until harvest.

Stability of MTHF. FTHF is known to be stable in culture. To determine the stability of MTHF in culture, ovine hepatocytes were cultured as above except that the media was Dulbecco's MEM/F12 without phenol red (Specialty Media, Phillipsburg, NJ, U.S.A.). The media was supplemented with 500 nM MTHF. Cells were cultured in a T75 flask with $40 \mathrm{~mL}$ of media. Aliquots of $10 \mathrm{~mL}$ of media were removed at $0,0.5,2$, and $24 \mathrm{~h}$. The media was acidified with $1 \mathrm{~N} \mathrm{HCl}$ to a $\mathrm{pH}$ of approximately 2.0 , and the acidified media was immediately added to a tube containing $60 \mathrm{mg}$ of sodium borodeuteride to stabilize the MTHF. This results in reduction of the MTHF to 5-methyl- $\left[\mathrm{CH}_{2} \mathrm{D}\right]-\mathrm{THF}$. The reaction was terminated with stepwise addition of $4 \mathrm{~mL}$ of $1 \mathrm{~N} \mathrm{HCl}$ (to $\mathrm{pH} 3.0$ ) after $30 \mathrm{~min}$. The samples were then desalted using a C18 resin $(100 \mathrm{mg})$ in a column. The column was washed with 4 vol of $0.01 \mathrm{~N} \mathrm{HCl}$, and eluted three times with $0.5 \mathrm{~mL}$ of methanol containing $1.0 \% \mathrm{vol} / \mathrm{vol} \beta$-mercaptoethanol. Samples were dried overnight under vacuum, covered, and stored protected from light at room temperature until assay. The dried samples were resuspended in $200 \mu \mathrm{L}$ of argon-treated deionized water, and $10 \mu \mathrm{L}$ was injected and analyzed on a Finnigan LC/MS (Finnigan, Palo Alto, CA, U.S.A.) using the electrospray ionization mode. Ions were monitored on the negative pole. The predicted $[\mathrm{M}-\mathrm{H}]^{-1}$ for MTHF converted to 5-methyl- $\left[\mathrm{CH}_{2} \mathrm{D}\right]$ THF is 459 whereas the predicted $[\mathrm{M}-\mathrm{H}]^{-1}$ for native 5 -meth$\mathrm{yl}-\left[\mathrm{CH}_{3}\right]$-THF is 458 .

Stable isotope studies. For stable isotope studies, hepatocytes were cultured for $24 \mathrm{~h}$ in low-folate media supplemented 
with the folate cofactor of interest. The media was refreshed with the same media and either $1-\left[{ }^{13} \mathrm{C}_{1}\right]$ serine or $1-\left[{ }^{13} \mathrm{C}_{1}\right]$ glycine at approximately $10 \%$ enrichment for a further $24 \mathrm{~h}$. Media was harvested at 0 and $24 \mathrm{~h}$, cellular debris was removed by centrifugation, and the media was snap-frozen on dry ice and stored at $-80^{\circ} \mathrm{C}$ until analysis. Serine and glycine ${ }^{13} \mathrm{C}$ media mole percent enrichment and concentration were determined at 0 and $24 \mathrm{~h}$ by GC/MS $(11,12)$. Serine and glycine interconversion, production, and utilization rates were determined by stable isotope dilution as we have previously described $(11,12)$.

Bromodeoxyuridine labeling of hepatocytes. To assess the effect of supplementation of hepatocytes with the folate cofactors on cellular division, we determined the incorporation of BrdU by immunohistochemistry. Cells were cultured as above in low-folate media with or without $500 \mathrm{nM}$ supplemental folate cofactors and $80 \mu \mathrm{M}$ BrdU for $24 \mathrm{~h}$. The cells were washed three times with PBS and fixed in methanol/0.3\% hydrogen peroxide. After treatment with $2 \mathrm{~N} \mathrm{HCl}$ and washing with PBS, BrdU-labeled cells were detected by immunohistochemical detection using Becton-Dickinson (San Jose, CA, U.S.A.) mouse anti-BrdU antibody and detection by $3,3^{\prime}-$ diaminobezidine using the universal peroxidase kit from Vector Laboratories, Inc. (Burlingame, CA, U.S.A.). Cells were then counterstained with hematoxylin, and 100 cells per well were counted in triplicate per condition by a single investigator (M.R.N.) blinded to the treatments.

Assays. Cellular DNA was determined by fluorimetry after solubilization in $1 \%$ SDS (24). Protein was determined by the method of Lowry et al. (25) as modified by/Hartree (26). Cytosolic extracts were prepared from hepatocytes as previously described (14). SHMT activity was determined by the method of Geller and Kotb (27). MTHFS was determined by the method of Girgis et al. (15).

Statistics. Data are presented as mean \pm SD or SEM. Comparisons among groups were made by paired $t$ test with significance taken at $p=0.05$.

\section{RESULTS}

Stability of MTHF. MTHF was readily detectable by direct probe GC/MS in culture media after 0.5 and $2 \mathrm{~h}$ on fetal ovine hepatocytes (Fig. 2) and was present at low levels of detection even after $24 \mathrm{~h}$ of culture.

Effect of folate cofactors on serine metabolism. The effect of supplementation with $50 \mathrm{nM}$ of the various folate cofactors on serine metabolism is shown in Tables 1 and 2. Under standard low-folate conditions, serine production exceeded utilization, resulting in a net serine production. Supplementation with $50 \mathrm{nM}$ MTHF results in a significant reduction in serine utilization compared with low folate. The result is an increase in net serine production compared with low folate. In contrast, $50 \mathrm{nM}$ 6S-FTHF results in a reduction in serine production compared with low folate. There was no effect on serine and glycine interconversion percentages (Table 2).

Effect of folate cofactors on glycine metabolism. The effect of supplementation with $50 \mathrm{nM}$ of the various folate cofactors on glycine metabolism is shown in Tables 1 and 2. Under

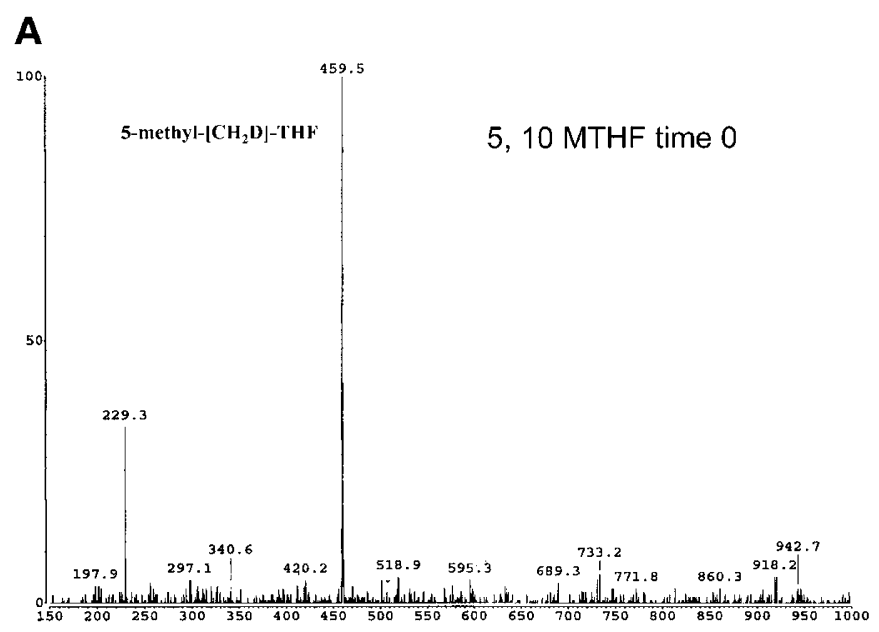

B

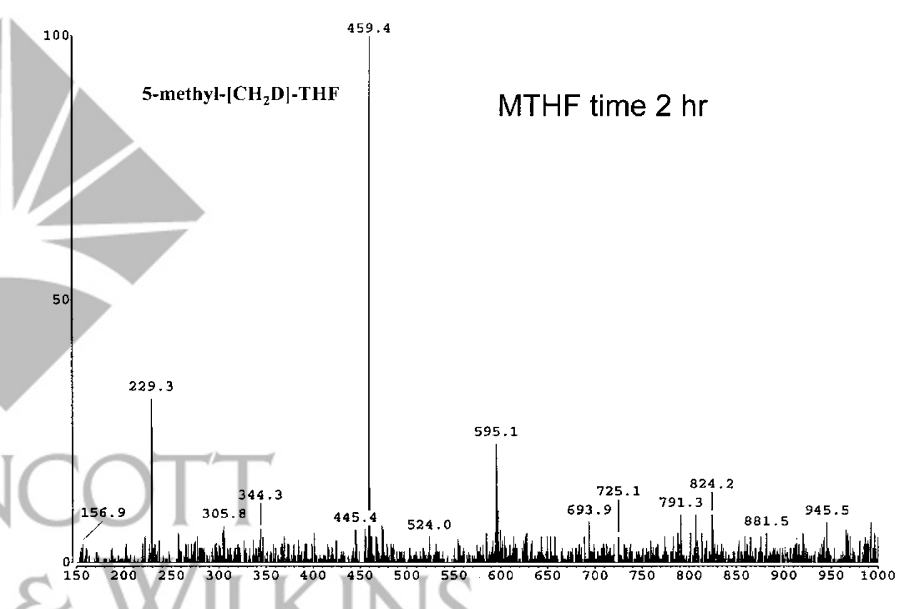

Figure 2. Persistence of MTHF in culture. Direct probe MS analysis of media supplemented with $500 \mathrm{nM}$ MTHF before (time $0 \mathrm{~h}, A$ ) and after application for $2 \mathrm{~h}$ (time $2 \mathrm{~h}, B$ ) on fetal ovine hepatocytes. Media preparation and extraction is outlined in the text. Note the strong peak at M/Z 459 representing the 5-methy- $\left[\mathrm{CH}_{2} \mathrm{D}\right]-\mathrm{THF}$ derivative of MTHF.

low-folate conditions, glycine utilization exceeded production with net glycine utilization. There were no changes in glycine metabolism with $50 \mathrm{nM}$ MTHF or FTHF. However, there was a significant difference between glycine production and utilization between MTHF- and FTHF-supplemented cultures (Table 1).

Concentration effect of folate cofactors on serine and glycine metabolism. Increasing the media concentration of MTHF (50 to $2000 \mathrm{nM}$ ) did not further affect the changes in serine metabolism (Fig. 3). However, increasing FTHF concentrations (50-2000 nM) did cause a further decrease in both serine production and utilization (Fig. 3). Increasing MTHF concentrations to $500 \mathrm{nM}$ did result in further increases in glycine production and utilization that declined at $2000 \mathrm{nM}$ (Fig. 4). In contrast, there was no effect of increasing concentrations of FTHF (up to $2000 \mathrm{nM}$ ) on glycine production or utilization (Fig. 4).

Effect of folate cofactors on SHMT and MTHFS. One mechanism by which folate cofactors might affect the changes in serine and glycine biosynthesis would be through modulation of the specific activity of SHMT or MTHFS. The activity 
Table 1. Effect of folate cofactor supplementation on serine and glycine metabolism*

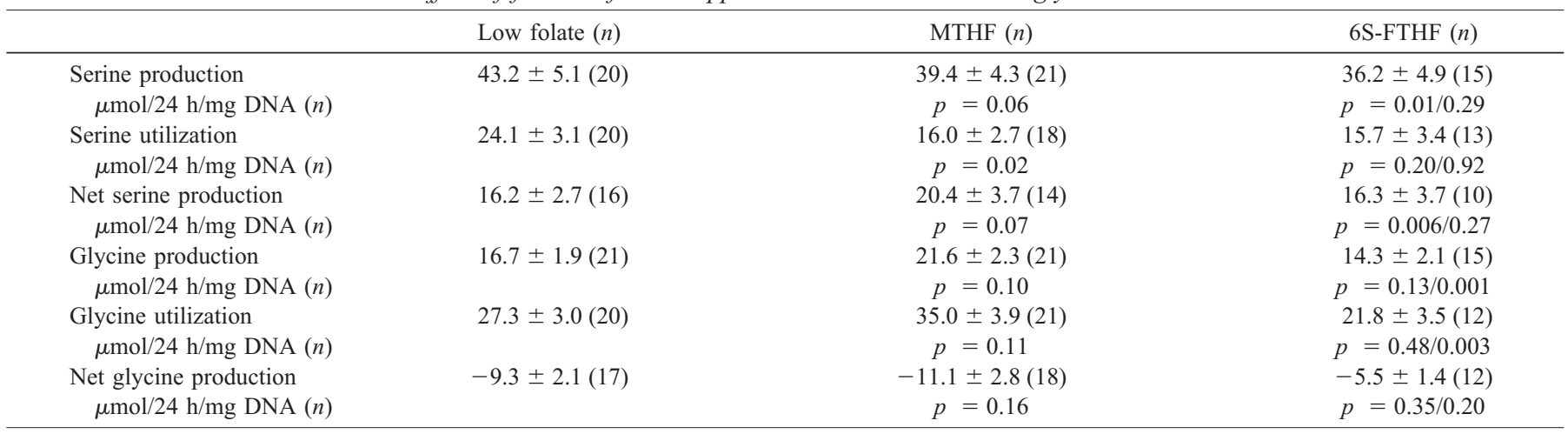

* After preconditioning in low-folate media for $24 \mathrm{~h}$, hepatocytes were cultured for $24 \mathrm{~h}$ with $50 \mathrm{nM}$ of the indicated factor. Serine and glycine production and utilization were determined by stable isotope dilution. Values are mean \pm SEM. Comparisons were by paired $t$ test between cultures performed in parallel (thus not necessarily all values compared). The $p$ values for MTHF are for comparison with low-folate media; $p$ values for 6S-FTHF are for comparison with low-folate/MTHF.

Table 2. Effect of folate cofactors on serine and glycine interconversion*

\begin{tabular}{lcccc}
\hline \multicolumn{1}{c}{ Media } & \% Ser C to Gly & \% Gly P from Ser & \% Gly C to Ser & \% Ser P from Gly \\
\hline Low folate & $53 \pm 31(9)$ & $53 \pm 16(8)$ & $48 \pm 35(17)$ & $41 \pm 30(15)$ \\
MTHF & $65 \pm 34(10)$ & $51 \pm 22(8)$ & $54 \pm 38(18)$ & $43 \pm 31(18)$ \\
6S-FTHF & $54 \pm 37(6)$ & $65 \pm 22(5)$ & $77 \pm 20(11)$ & $60 \pm 27(13)$ \\
\hline
\end{tabular}

* After preconditioning in low-folate media for $24 \mathrm{~h}$, hepatocytes were cultured for $24 \mathrm{~h}$ with no supplemental folate cofactor or $50 \mathrm{nM}$ of MTHF or $6 \mathrm{~S}$-FTHF. Serine and glycine interconversion was determined by stable isotope methodology as outlined in the text. Values are mean \pm SD for $(n)$ samples.

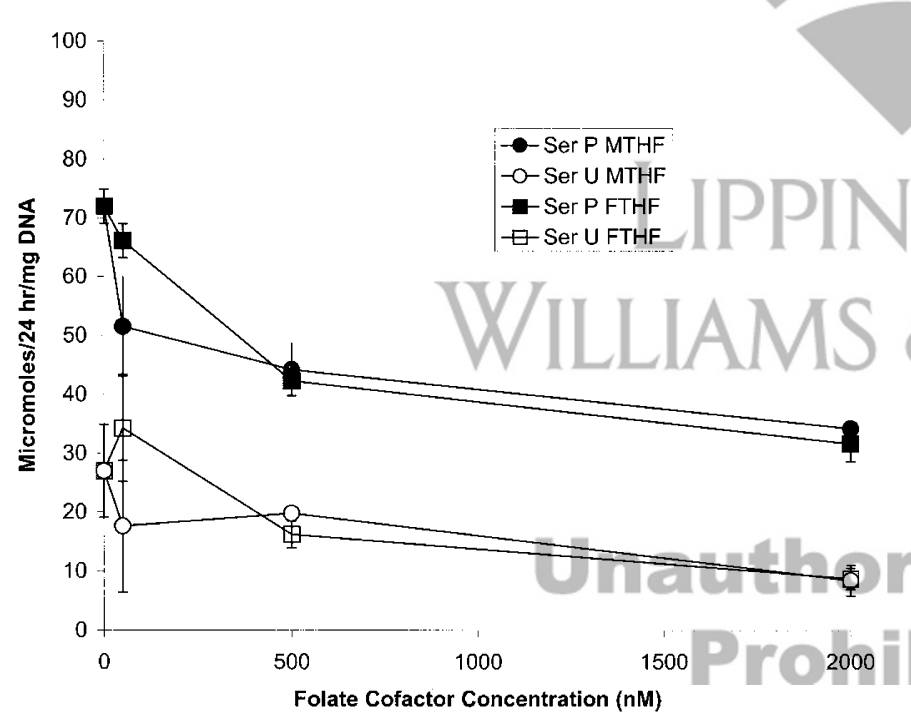

Figure 3. Concentration effect of folate cofactors on serine metabolism. Fetal ovine hepatocytes were cultured in the presence of increasing doses of MTHF or FTHF. Serine $(S e r)$ production $(P)$ and utilization $(U)$ were determined by $\mathrm{GC} / \mathrm{MS}$ and stable isotope tracing as outlined in the text. Values are mean \pm SD for three determinations.

of SHMT and MTHFS were not affected by culture in lowfolate media compared with standard media $(1 \mu \mathrm{M}$ folate $)$ or low-folate media supplemented with $50 \mathrm{nM}$ MTHF or $50 \mathrm{nM}$ $6 \mathrm{R}+\mathrm{S}$ FTHF (Table 3).

Effect of folate cofactors on BrdU labeling. There was a significant increase in BrdU labeling in cells cultured in lowfolate media supplemented with $500 \mathrm{nM}$ MTHF compared with cells cultured in low-folate media or low-folate media supplemented with either 5-methyl-THF or 6S-FTHF $(p<0.0005$; Fig. 5).

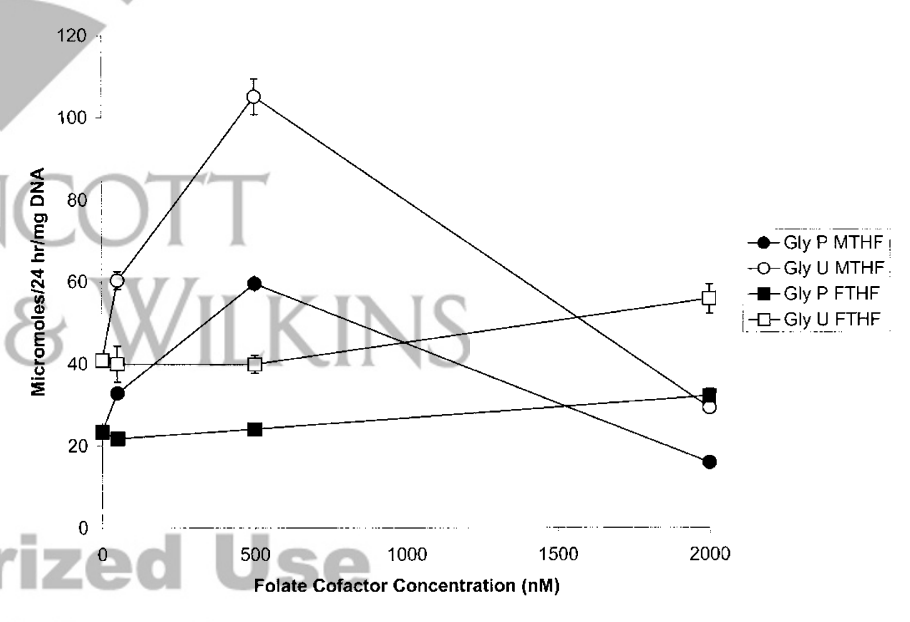

Figure 4. Concentration effect of folate cofactors on glycine metabolism. Fetal ovine hepatocytes were cultured in the presence of increasing doses of MTHF or FTHF. Glycine $(G l y)$ production $(P)$ and utilization $(U)$ were determined by GC/MS and stable isotope tracing as outlined in the text. Values are mean \pm SD for three determinations.

Effect of hormonal supplementation on serine and glycine metabolism. The effect of hormonal supplementation on serine and glycine metabolism is shown in Table 4. Insulin treatment $(1 \mu \mathrm{M})$ results in a generalized increase in all variables compared with no insulin treatment. Glucagon specifically increased serine utilization with no effect on serine production.

\section{DISCUSSION}

To date, the regulation of fetal hepatic serine biosynthesis has been unclear. Others and we have demonstrated that glycine, glycolytic intermediates, and glucose are the primary precursors for the unique net fetal hepatic serine biosynthesis 
Table 3. Activity of MTHFS and folate supplementation*

\begin{tabular}{lcc}
\hline Media/condition & $\begin{array}{c}\text { SHMT } \\
(\mathrm{nmol} / \mathrm{min} / \mathrm{mg} \text { protein })\end{array}$ & $\begin{array}{c}\text { MTHFS } \\
(\mathrm{nmol} / \mathrm{min} / \mathrm{mg} \text { protein })\end{array}$ \\
\hline Native liver & $21.1 \pm 9.3$ & $0.197 \pm 0.122$ \\
Standard media & $12.1 \pm 2.3$ & $0.064 \pm 0.026$ \\
Low-folate media & $12.6 \pm 3.4$ & $0.087 \pm 0.032$ \\
5,10 MTHF & $15.1 \pm 1.7$ & $0.032 \pm 0.017$ \\
6 R + S FTHF & $11.9 \pm 0.9$ & $0.115 \pm 0.067$ \\
\hline
\end{tabular}

* Values are mean $\pm \mathrm{SD}$ of three separate determinations.

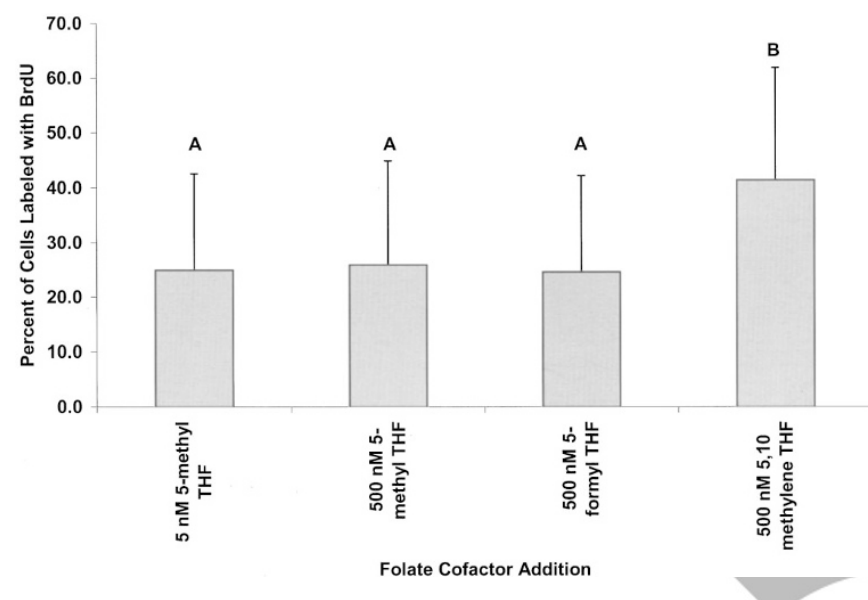

Figure 5. Effect of folate cofactor supplementation on BrdU labeling. Fetal ovine hepatocytes were cultured for $24 \mathrm{~h}$ in low-folate media or media supplemented with $500 \mathrm{nM}$ of the indicated folate cofactor. BrdU labeling was determined as detailed in the text. Different letters indicate significant differences. B was significantly different from A by paired two-tailed $t$ test at $p<$ 0.0005 .

Table 4. Effect of insulin and glucagon on serine and glycine metabolism (percent of low-folate values)*

\begin{tabular}{|c|c|c|}
\hline & Insulin & Glucagon $1 \mu \mathrm{M}$ \\
\hline Serine production & $254 \pm 116(p=0.009)$ & $121 \pm 45(p=0.15)$ \\
\hline Serine utilization & $403 \pm 206(p=0.006)$ & $260 \pm 65(p=0.0004)$ \\
\hline Glycine production & $206 \pm 65(p=0.03)$ & $142 \pm 48(p=0.04)$ \\
\hline Glycine utilization & $200 \pm 92(p=0.02)$ & $170 \pm 62(p=0.02)$ \\
\hline
\end{tabular}

* After preconditioning in LF media for $24 \mathrm{~h}$, hepatocytes were cultured for $24 \mathrm{~h}$ with or without $1 \mu \mathrm{M}$ of the indicated hormone. Glycine and serine production and utilization were determined by stable isotope dilution. Values are mean $\pm \mathrm{SD}$. Comparisons with low folate were by paired $t$ test.

$(11,28)$. The primary metabolic pathway involved is SHMT and the glycine cleavage system (12).

In this study, we have demonstrated that, in fetal ovine hepatocytes, provision of excess MTHF leads to a direct reduction in serine utilization and an increase in net serine production. Inasmuch as MTHF is the primary folate cofactor for serine biosynthesis from glycine via SHMT, this would be consistent with continued flux of glycine to serine via SHMT with a concomitant decrease in the flux of serine to glycine. However, the reduction in serine utilization is not solely isolated to the flux through SHMT, as the overall percentage of serine carbon used for glycine synthesis did not change (Table 2). As serine to glycine conversion via SHMT is a major pathway for serine utilization $(11,12)$, the net result of MTHF supplementation is a decrease in glycine production from serine. Previous work by Girgis et al. (15) has shown that increasing MTHF by overexpression of MTHFS led to an increase in serine accumulation. This work confirms their finding and extends the observation to demonstrate that extracellular MTHF can also lead to an increase in serine, primarily owing to a decrease in serine utilization.

Supplementation with $50 \mathrm{nM}$ FTHF results in a decrease in serine production (Table 1). In neuroblastoma cells, FTHF excess did reduce serine levels (15). Although polyglutamated FTHF is a known slow tight binder of SHMT (29), the mechanism by which extracellular FTHF might influence serine production is unclear. Cellular transport of FTHF appears to be via the reduced folate carrier (30). Thus, intracellular FTHF might increase serine to glycine flux through SHMT to increase the relative abundance of MTHF. The dose response for FTHF on both serine and glycine metabolism does suggest that transport of FTHF is a factor in the regulation of serine and glycine metabolism. Another possible mechanism would be internalization and polyglutamation of FTHF with resultant inhibition of SHMT and a reduction in the flux through SHMT. Whatever the mechanism, this work does parallel the work of Girgis et al. (15), demonstrating a lower rate of serine production with FTHF supplementation.

Provision of these cofactors at $50 \mathrm{nM}$ does not alter serine biosynthesis by altering enzyme activity (Table 3 ). Thus, the increase in serine production is most likely directly related to the provision of excess cofactor.

There is an additional biologic effect of supplementation with MTHF. Cellular division as determined by BrdU labeling is specifically increased with supplementation with MTHF but not with 5-methyl-THF or FTHF. Thus MTHF may regulate the availability of one-carbon precursors for DNA synthesis and cellular division. This provides another mechanism by which folate cofactors and serine metabolism may interact to affect fetal growth.

At birth, there is a shift from net fetal hepatic serine production to net utilization. As many of the changes in metabolism that occur at birth are regulated by changes in glucagon and insulin concentrations $(23,31,32)$, we sought to determine the effect of these hormones on serine metabolism. Glucagon treatment dramatically increased serine utilization, converting the ovine hepatocytes to net serine utilization. Although insulin did not alter the net metabolism of serine, it did increase both serine production and utilization. These findings are consistent with a role for glucagon in regulation of the change in hepatic serine metabolism that occurs at birth. The up-regulation of utilization is most likely related to an increase in the utilization of serine for gluconeogenesis. However, the effect of glucagon on folate cofactor supply has not been investigated.

\section{CONCLUSIONS}

In this study, we have demonstrated a direct relationship between fetal serine metabolism and specific folate cofactor availability. We speculate that fetal serine metabolism may be a reflection of the fetal folate status. In that regard, it is of interest that intrauterine growth-retarded human fetuses have low serine levels $(9,10)$. This study has demonstrated that fetal hepatic serine metabolism is regulated in part by the availability of folate cofactors and the balance of insulin and glucagon, 
and provides the clues to suggest that abnormalities of fetal serine metabolism may be related to fetal folate status and might impact fetal growth.

\section{REFERENCES}

1. Cetin I, Fennessey PV, Sparks JW, Meschia G, Battaglia FC 1992 Fetal serine fluxes across the fetal liver, hindlimb and placenta in late gestation: the role of fetal serine in placental glycine production. Am J Physiol 263:E786-E793

2. Cetin I, Sparks JW, Quick ANJ, Marconi AM, Meschia G, Battaglia FC, Fennessey PV 1991 Glycine turnover and oxidation and hepatic serine synthesis from glycine in fetal lambs. Am J Physiol 260:E371-E378

3. Moores RR, Rietberg CCT, Battaglia FC, Fennessey PV, Meschia G 1993 Metabolism and transport of maternal serine by the ovine placenta: glycine production and absence of serine transport into the fetus. Pediatr Res 33:590-594

4. Moores Jr RR, Carter BS, Meschia G, Fennessey PV, Battaglia FC 1994 Placental and fetal serine fluxes at midgestation in the fetal lamb. Am J Physiol 267:E150-E155

5. Sturman JA, Gaull GE, Raiha NCR 1975 DNA synthesis from the $\beta$-carbon of serine by fetal and mature human liver. Biol Neonate 27:17-22

6. Xu Z, Byers DM, Palmer FB, Spence MW, Cook HW 1991 Serine utilization as a precursor of phosphatidylserine and alkenyl-(plasmenyl)-, alkyl-, and acylethanolamine phosphoglycerides in cultured glioma cells. J Biol Chem 266:2143-2150

7. Marconi AM, Battaglia FC, Meschia G, Sparks JW 1989 A comparison of amino acid arteriovenous differences across the liver and placenta of the fetal lamb. Am J Physiol 257:E909-E914

8. Cetin I, Marconi A, Baggiani A, Buscaglia M, Pardi G, Fennessey P, Battaglia F 1995 In vivo placental transport of glycine and leucine in human pregnancies. Pediatr Res 37:571-575

9. Cetin I, Marconi AM, Bozzetti P, Sereni LP, Corbetta C, Pardi G, Battaglia FC 1988 Umbilical amino acid concentrations in appropriate and small for gestational age infants: a biochemical difference present in utero. Am J Obstet Gynecol 158:120-126

10. Cetin I, Corbetta C, Sereni LP, Marconi AM, Bozzetti P, Pardi G, Battaglia FC 1990 Umbilical amino acid concentrations in normal and growth retarded fetuses sampled in utero by cordocentesis. Am J Obstet Gynecol 162:253-261

11. Narkewicz MR, Thureen PJ, Sauls SD, Tjoa S, Nikolayevsky N, Fennessey PV 1996 Serine and glycine metabolism in hepatocytes from mid-gestation fetal lambs. Pediatr Res 39:1085-1090

12. Thureen PJ, Narkewicz MR, Battaglia FC, Tjoa S, Fennessey PV 1995 Pathways of serine and glycine metabolism in primary culture of ovine fetal hepatocytes. Pediatr Res 38:775-782

13. Narkewicz MR, Moores RVJ, Battaglia FC, Frerman FF 1999 Ontogeny of serine hydroxymethyltransferase isoenzymes in fetal sheep liver, kidney and placenta. Mol Genet Metab 68:473-480

14. Narkewicz MR, Sauls SD, Tjoa SS, Teng C, Fennessey PV 1996 Evidence for intracellular partitioning of serine and glycine metabolism in Chinese hamster ovary cells. Biochem J 313:991-996
15. Girgis S, Suh JR, Jolivet J, Stover PJ 1997 5-Formyltetrahydrofolate regulates homocysteine remethylation in human neuroblastoma. J Biol Chem 272:4729-4734

16. Landon MJ, Eyre DH, Hytten FE 1975 Transfer of folate to the fetus. Br J Obstet Gynaecol 82:12-19

17. Thompson HR, Jones GM, Narkewicz MR 2001 Ontogeny of hepatic enzymes involved in serine- and folate-dependent one-carbon metabolism in rabbits. Am J Physiol Gastrointest Liver Physiol 280:G873-G878

18. Townsend SF, Thureen PJ, Hay WWJ, Narkewicz MR 1993 Development of primary culture of ovine fetal hepatocytes for studies of amino acid metabolism and insulinlike growth factors. In Vitro Cell Dev Biol Anim 29A:592-596

19. Narkewicz MR, Jones G, Morales D 2000 Serine and glycine transport in fetal ovine hepatocytes. Biochim Biophys Acta 1474:41-46

20. Spedale S, Battaglia F, Sparks J 1992 Amino acid utilization by the gut and liver after milk feeding in the newborn lamb. Pediatr Res 31:53A

21. Bismut H, Plas C 1991 Role of serine biosynthesis and its utilization in the alternative pathway from glucose to glycogen during the response to insulin in cultured foetal-rat hepatocytes. Biochem J 276:577-582

22. Cheung GP, Cotropia JP, Sallach HJ 1968 Comparative studies of enzymes related to serine metabolism in fetal and adult liver. Biochim Biophys Acta 170:334-340

23. Girard J, Ferre P, Kervran A, Pegorier JP, Assan R 1977 Role of the insulin/glucagon ratio in the changes of hepatic metabolism during the development of the rat. In: Foa P, Bajaj J, Foa N (eds) Glucagon: Its Role in Physiology and Clinical Medicine. Springer-Verlag, New York, pp 563-581

24. Labarca C, Paigen K 1980 A simple, rapid, and sensitive DNA assay procedure. Anal Biochem 102:344-352

25. Lowry OH, Rosebrough NJ, Farr AL, Randall RJ 1951 Protein measurement with the Folin phenol reagent. J Biol Chem 193:265-275

26. Hartree EF 1972 Determination of protein: a modification of the Lowry method that gives a linear photometric response. Anal Biochem 48:122-127

27. Geller AM, Kotb MY 1989 A binding assay for serine hydroxymethyltransferase. Anal Biochem 180:120-125

28. Bismut H, Poggi-Bach J, Plas C 1992 Consumption and production of amino acids by insulin-responsive cultured fetal rat hepatocytes: the particular case of serine. Biol Neonate 62:37-46

29. Stover P, Schrich V 1991 5-Formyltetrahydrofolate polyglutamates are slow tight binding inhibitors of serine hydroxymethyltransferase. J Biol Chem 266:15431550

30. Jansen G, Westerhof GR, Jarmuszewski MJ, Kathmann I, Rijksen G, Schornagel JH 1990 Methotrexate transport in variant human CCRF-CEM leukemia cells with elevated levels of the reduced folate carrier: selective effect on carrier-mediated transport of physiological concentrations of reduced folates. J Biol Chem 265:1827218277

31. Girard J, Perdereau D, Narkewicz M, Coupe C, Ferre P, Decaux JF, Bossard P 1991 Hormonal regulation of liver phosphoenolpyruvate carboxykinase and glucokinase gene expression at weaning in the rat. Biochimie 73:71-76

32. Narkewicz MR, Iynedjian P, Ferre P, Girard J 1991 Insulin and triiodothyronine induce glucokinase mRNA in primăry cultures of neonatal rat hepatocytes. Biochem J 271:585-589

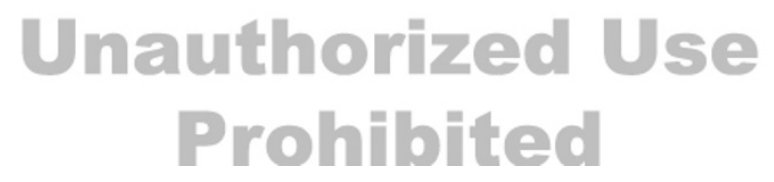

